encuentro con el profesor de toda la vida. Luego de haber procesado medianamente la pena de su partida, me siento feliz de haber compartido tantos años con él.

Luis Orlandini Robert

Músico

Académico del Departamento de Música y Sonología de la

Facultad de Artes de la Universidad de Chile Miembro de Número de la Academia Chilena de Bellas Artes del Instituto de Chile lorlandini@uchile.cl

\title{
Sylvia Ofelia Urbina Pinto \\ (Valparaíso, 4 de enero de 1928 - Santiago, 18 de enero de 2016)
}

Luego de pasar su infancia en Valparaíso con su familia de manifiesta cultura musical, viaja a Santiago para estudiar y titularse de profesora normalista. Su interés por la música la llevó a asistir a varios de los cursos de Margot Loyola en las Escuelas de Temporada que impartía en la Universidad de Chile a fines de los años 40 y comienzos de los 50. En esa época también integra el Coro Pablo Vidales, con el que asiste al Festival Internacional de las Juventudes Mundiales realizado en Bucarest, Rumania. La delegación chilena que concurrió a ese encuentro organizó de manera improvisada un conjunto folclórico, el que alcanzó resultados discretos. No obstante, después de regresar al país, varios de sus integrantes -Rolando Alarcón, Alejandro Reyes y la propia Silvia Urbina-, entre otros, se inscribieron en una nueva versión de los cursos de Margot Loyola, en la que nació el "Conjunto de alumnos de Margot Loyola”, que posteriormente pasó a llamarse el Conjunto Cuncumén. El grupo se transformó rápidamente en un referente en la presentación escénica del canto tradicional chileno, además de uno de los emblemas del movimiento conocido como "Proyección folclórica", el que durante los años 50 tuvo a Margot Loyola y Violeta Parra como sus máximos exponentes.

En sus seis años como integrante de Cuncumén (1955-1961), Sylvia Urbina participó en la grabación de cuatro LP, en los que destacó por su capacidad interpretativa como cantante solista y en dúo junto a Helia Fuentes y a Rolando Alarcón. El grupo además participó en varias giras internacionales. La primera se realizó a Brasil en 1955 y las dos siguientes a algunos de los entonces países socialistas europeos en 1957 y 1961. Después de 1961 Sylvia Urbina dejó el Cuncumén, según explicaba, para dedicarse a la enseñanza musical de los niños. Durante los años que lo integró, el conjunto adquirió una fisonomía que se volvió un modelo para centenares de otras agrupaciones que replicaron el modelo de conjunto mixto y reprodujeron desde su repertorio hasta sus arreglos vocales e instrumentales, sus vestimentas y su puesta en escena. Incluso sus integrantes apadrinaron a varios conjuntos que entonces daban sus primeros pasos. A modo de ejemplo Sylvia Urbina fue, entre otros, la maestra del grupo Lonquimay, que lideraba Richard Rojas y que posteriormente pasó a llamarse Lonqui.

Luego de su salida de Cuncumén, Urbina trabajó en 1963 en un espectáculo llamado "Imagen de Chile" bajo la dirección de Eugenio Dittborn. Con este recorrió el continente americano presentando una muestra de cantos y danzas chilenas con la participación de actores y músicos como Los Huasos Quincheros, Los de Ramón, el trío Paupalú, Rolando Alarcón y otros. Ese mismo año salieron los primeros fonogramas de su dúo con Rolando Alarcón, un disco single de canciones rusas, y en 1964 editaron un medio LP, en pleno boom del movimiento conocido como Neofolklore, renovador en la escena musical chilena. El dúo participó además en el disco Patría mía, dirigido por Ariel Arancibia, que incluía canciones que fueron parte del espectáculo del Clásico Universitario de $1964^{1}$.

1 Este término se refiere a un partido de fútbol que se jugaba en el Estadio Nacional de día (en invierno) o de noche (en primavera) entre los conjuntos profesionales de la Universidad de Chile y la Universidad Católica, precedido por un espectáculo escénico con música que se presentaba en la cancha del estadio. 
Junto a su trayectoria como artista, Silvia Urbina empezó muy temprano su trabajo como educadora con algunos alumnos de la Escuela $\mathrm{N}^{\circ} 21$ República de Cuba de la entonces población Colo Colo de Santiago, el que hoy día es el Liceo Luis Calvo Mackenna. Con ellos formó el que ha sido considerado el primer conjunto folclórico infantil: los Cuncumenitos. Poco después de concluir el dúo con Rolando Alarcón, quien inició su carrera como solista, Sylvia Urbina coronó el trabajo de varios años con sus niños con un LP grabado a mediados de los 60, para el que los menores compusieron y desarrollaron habilidades que iban más allá de lo musical. "Yo no quería enseñarles folclore, quería que a través del folclore tuvieran herramientas para la vida", aseguraba la artista hace pocos años en una entrevista para el programa "Acordes mayores" en Radio Cooperativa.

A partir de su matrimonio con Patricio Manns, la intérprete tuvo su época de mayor exposición en la escena musical chilena. Juntos editaron el LP El folklore no ha muerto, $m$... interpretando temas de Manns y del folclore. En ese trabajo figura la primera grabación de "El cautivo de Til Til", que el cantautor dedicó a la figura de Manuel Rodríguez y que años más tarde se volvería una creación esencial del cancionero chileno. A pesar del nombre del disco, que pretende hacer una defensa de la tradición campesina de Chile, especialmente en los temas de Manns se aprecian innovaciones en las interpretaciones vocales de algunos temas y en ciertos elementos que serían clave en la Nueva Canción Chilena. Entre ellos se puede señalar la incorporación de ritmos latinoamericanos y su interpretación con instrumentos supuestamente ajenos a la zona geográfica original de la creación musical. Este es el caso de "Alegres eran mis ojos", interpretado con charango e inspirado en un ritmo venezolano, o la utilización del cuatro en la cueca dedicada al aviador Luis Acevedo.

En 1969 Sylvia Urbina publica el único larga duración que hizo como solista, Los barcos en la noche, también con la importante colaboración de Patricio Manns y la interpretación de numerosos temas tradicionales. El disco cuenta con la participación de una orquesta dirigida por Valentín Trujillo y de destacados músicos nacionales como Alberto Rey e Iván Cazabón. Se aprecia una versatilidad similar al del trabajo anterior en términos de repertorio y arreglos instrumentales, que también exigen de Sylvia Urbina un amplio manejo para enfrentar diversos estilos interpretativos en términos vocales y de manejo rítmico de la guitarra.

Luego de este disco Urbina no vuelve a hacer grabaciones solistas y se concentra en presentaciones en vivo y especialmente en su trabajo de crianza y educación de su hijo Ian Manns Urbina, quien fue la mejor muestra de su ejemplar trabajo de enseñanza de la música en menores con discapacidades. Aplicando el método Suzuki y el que ella denominaba "Método por colores" consiguió avances insospechados en niños que, incluso, a fines de los años 70 conformaron el conjunto folklórico Trigal, que tuvo algunas presentaciones públicas con bastante éxito. Este trabajo se cristalizó durante varios años en una academia que mantuvo en su casa ubicada en la calle Obispo Orrego, en la comuna de Ñunoa. En paralelo ella seguía con sus actuaciones, especialmente en actos solidarios y de resistencia al gobierno de turno. A comienzos de los 90 participó en el registro de una cassette en homenaje a Rolando Alarcón, en el que grabó tres canciones con el acompañamiento del grupo Aranto dirigido por Fernando Carrasco.

En sus últimos años, Urbina realizó presentaciones esporádicas junto al grupo Cantalao, que tuvo diversos integrantes y que tomó el nombre de su grupo infantil de los años 60, luego que por razones legales no pudieran continuar bajo la denominación de Los Cuncumenitos. Este quehacer artístico lo combinó con su participación activa en el Sindicato de Folkloristas de Chile y con la presidencia de la Asociación Nacional de Folklore, Anfolchi. Además, fue integrante del Consejo del Fomento de la Música Nacional como representante de los intérpretes folclóricos.

Sus últimos años fueron también pródigos en reconocimientos. En 2004 recibió el Premio Nacional de Folklore por parte del Sindicato de Folkloristas de Chile, en 2012 obtuvo una pensión de gracia de parte del entonces Primer Mandatario Sebastián Piñera y en 2013 ganó el premio Presidente de la República en el rubro Música de Raíz Folklórica por su destacada trayectoria. En 2012, en tanto, tuvo una de sus más recordadas presentaciones en público cuando cantó junto a Helia Fuentes, otra fundadora de Cuncumén, en la gala de folclore que organizó el Sindicato de Folkloristas en el Teatro Municipal. $\mathrm{Al}$ año siguiente realizó su última participación discográfica cuando acompañó al dúo Alycanto en "El amor es un niñito", del repertorio de Cuncumén, para un disco del dúo con temática navideña.

El viernes 22 de enero de 2016 Silvia Urbina junto a Cantalao, Helia Fuentes y la cantora y payadora Cecilia Astorga tenían que ofrecer un recital en el Museo Violeta Parra, gracias a una invitación de la familia Parra que quería reconocer su proximidad con la más importante creadora del país. Pese a 
que mostraba un impecable estado de salud a sus 88 años cumplidos, el 18 de enero se informó de su deceso. Debido a ello ese espectáculo se transformó en el primer homenaje para una de las cantantes más relevantes del folclore chileno.

Manuel Vilches Parodi

Departamento de Música y Sonología, Facultad de Artes Universidad de Chile, Chile manuelvilchesp@uchile.cl

\section{Manuel Jiménez Godoy \\ (Santiago, abril de 1960 - 24 de abril de 2016)}

La partida de un grande

A los 56 años recién cumplidos, producto de un paro cardiorrespiratorio, falleció repentinamente el notable arpista nacional Manuel Jiménez Godoy, solista de la Orquesta Sinfónica de Chile por varias décadas, y egregio referente latinoamericano del arpa clásica a nivel internacional. Su muerte provocó un gran impacto en el mundo músical, en el que gozó de un aprecio transversal por sus extraordinarias cualidades artísticas y humanas.

Su formación inicial la realizó en el Departamento de Música de la actual Facultad de Artes de la Universidad de Chile con la profesora Teresa Tixier, continuó sus estudios en el extranjero, graduándose con honores en el Conservatorio Superior de París, uno de los más importantes del mundo.

Destacable fue su labor -de genuino apostolado- en difundir exitosamente la literatura para el arpa en la casi totalidad del territorio nacional. Asimismo, fue un permanente invitado como solista de importantes orquestas latinoamericanas.

De su época de aventajado estudiante, se tiene un gran recuerdo de su participación en 1978 en el Concierto para arpa, flauta y orquesta de Wolfang Amadeus Mozart con la Orquesta del Departamento de Música de la Facultad de Artes de la Universidad de Chile, bajo la dirección del recordado maestro austríaco Peter Richter de Rangenier, en la que demostró su innegable talento, que luego perfeccionaría en el extranjero. Doce años después, en 1990, volvió a interpretar esta obra con el destacado intérprete en flauta Alberto Almarza y la Orquesta Filarmónica de Santiago, en una versión magistral bajo la dirección del austríaco Dietfred Bernet, que ha sido calificada de "antológica".

Oportunidades de haberse desarrollado como solista con orquestas del primer mundo no le faltaron. No obstante, eligió regresar a su país de origen para desarrollarse profesionalmente y proyectar desde Chile su carrera internacional, como eximio intérprete de recitales y como solista con diferentes agrupaciones tanto de cámara como sinfónicas.

Reconocido por muchísimos maestros, Manuel Jiménez fue un miembro indispensable de la Orquesta Sinfónica de Chile (OSCH). Apoyó con excelencia todas las obras orquestales que requirieran arpa obligada. Asimismo frecuentemente tocó como solista en una buena parte del repertorio para arpa que presentara la OSCH, siempre con atronadores éxitos de público y con el reconocimiento unánime de la crítica especializada. De hecho, en sus treinta años como integrante de la OSCH, casi nunca se invitó a otro solista en arpa a participar en las temporadas oficiales de este conjunto.

Momentos claves de su carrera fue haber tocado en España con el arpa del legendario Nicanor Zabaleta, en una versión de culto del Concierto para arpa y orquesta de Alberto Ginastera, en el marco de la gira a dicho país que realizara la OSCH bajo la recordada dirección del maestro Irwin Hoffman, a la sazón titular de la agrupación. Posteriormente Manuel Jiménez intérpretó esta obra en una aclamada versión con la prestigiosa Orquesta Filarmónica de la Ciudad de México.

Otro hito de su carrera fue su participación en el estreno sudamericano del Concierto Máscaras del compositor mexicano Arturo Márquez, una obra actualmente indispensable en la literatura para arpa y orquesta. 